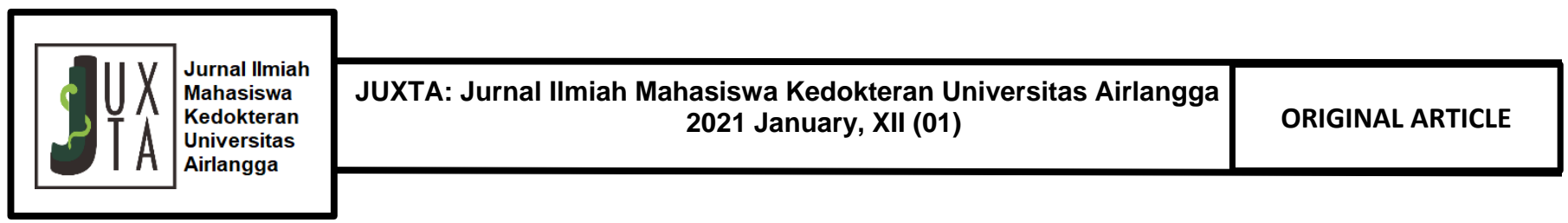

\title{
Correlation between Maternal Infection and Infant Cholestasis
}

\author{
Liofelita Christi Adhi Mulia ${ }^{1}$, I Gusti Made Reza Gunadi Ranuh ${ }^{2^{*}}$, Ernawati ${ }^{3}$
}

\begin{abstract}
${ }^{1}$ Faculty of Medicine, Universitas Airlangga, Surabaya, Indonesia.
${ }^{2}$ Department of Pediatrics, Faculty of Medicine, Universitas Airlangga/Dr. Soetomo General Hospital, Surabaya, Indonesia. ${ }^{3}$ Department of Obstetrics and Ginecology, Universitas Airlangga/Dr. Soetomo General Hospital, Surabaya, Indonesia.
\end{abstract}

\section{A B S T R A C T}

Introduction: Infant cholestasis has been associated to viral infection. Cytomegalovirus in the pathogenesis of neonatal hepatitis has been already known and it is one of the possible etiological of biliary atresia. The aim of this study was to outline the correlation between maternal infection and infant cholestasis (aged 0-1 year old) in Department of Pediatrics Dr. Soetomo General Hospital, Surabaya.

Methods: A case-control study of pregnant women who gave birth in Dr. Soetomo General Hospital from June 2016 to June 2017. The data were taken from medical records. The cases were defined as pregnant women with babies who had cholestasis, and the control was pregnant women who gave birth to a baby without cholestasis within the age of 0-1 year old. Sample cases in this study were drawn from the total population, with the inclusion criteria babies who had cholestasis, and exclusion criteria that include complications of pregnancy and a history of infant's parent with genetic disorders. The control variable studied was maternal infection history and sex. Samples were taken by purposive control. The data were obtained then summarized and analyzed by univariate and bivariate, using the chi-square table analysis.

Results: The number of cases that met the inclusion criteria were 68 patients, and the amount of control taken was 110 patients. The total number of patients studied was 178 patients. Univariate analysis found the cholestasis was more common in mother with infection during pregnancy $(73.53 \%$ from the total of cholestasis). Bivariate analyzes found relationship between pregnancy infection and cholestasis $(p=<0.001$, or $=20.726)$.

Conclusion: The maternal infection is significantly associated with cholestasis in infants.

* Correspondence: rezagunadi@gmail.com

JUXTA: Jurnal IImiah Mahasiswa Kedokteran Universitas Airlangga

p-ISSN: 1907-3623; e-ISSN: 2684-9453

DOI: 10.20473/juxta.V12I12021.38-41

Open access under Creative Commons Attribution-ShareAlike 4.0 International License (CC-BY-SA)

\section{ARTICLE INFO}

\author{
Article history: \\ Received 16 November 2020 \\ Received in revised form 1 \\ December 2020
}

Accepted 16 December 2020

\section{Keywords:}

Cholestasis,

Maternal Infection,

Case-control. 


\section{Introduction}

Cholestasis is a failure of normal bile flow into the duodenum. Clinically, cholestasis can be defined as the accumulation of substances excreted into bile such as bilirubin, bile acids, and cholesterol in the blood and body tissues. ${ }^{1}$

Based on the recommendations of the North American Society for Pediatric Gastroenterology, Hepatology and Nutrition (NASPGHAN) in 2009, it can be said as cholestasis if the direct bilirubin level is more than $1 \mathrm{mg} / \mathrm{dl}$ and if total bilirubin is less than $5 \mathrm{mg} / \mathrm{dl}$, whereas if the total bilirubin level is more than $5 \mathrm{mg} / \mathrm{dl}$, bilirubin levels are more than $20 \%$ of total bilirubin. ${ }^{2}$

In an infection that enters the liver or outside the liver, bacteria can produce endotoxins that can enter the circulation even though infecting bacteria do not enter the bloodstream. The condition of cholestasis can be found even though there is no bacteremia. Endocytin can stimulate cytokine synthesis by macrophages (in the liver such as kupffer cells). Kupffer cells and other immunocompetent cells in the liver synthesize intrahepatic cytokines such as TNF- $\alpha$, IL-1, IL-6, and IL-8, thus the number of intrahepatic cytokines increases, interferes with hepatocyte function, and causes cholestasis. Cytokines are also released by bile duct epithelial cells (cholangiocytes), namely TNF-alpha and IL-6. Hepatocytes and cholangiocytes apparently contribute actively to the response of proinflammatory cytokines. ${ }^{3}$

The most cause of infant cholestatis is billiary atresia (1 of 5.000-18.000 birth). ${ }^{4}$ The probable contributor are infection agent include rotavirus $\mathrm{C}$, retrovirus and human cytomegalovirus (HCMV). ${ }^{5-9}$ Based on Xu et al, 2017 study found that CD13-specific autoantibodies, known to be induced by HCMV infection, that exist in mothers of infant cholestasis but not in mothers of healthy infants. ${ }^{10}$

The incidence of cholestasis increases in infants with less gestational age and low birth weight babies, because it is associated with impaired liver function. Other risk factors associated with cholestasis are babies who experience recurrent sepsis and parenteral nutrition. ${ }^{11}$

A study in Child Inpatient Services at Dr. Soetomo General Hospital, Surabaya in 1999-2004 showed that out of 19,720 inpatients, it obtained 96 patients with neonatal cholestasis, 68 patients with neonatal hepatitis (70.8\%), 9 patients with biliary atresia $(9.4 \%), 5$ patients with coledocus-duct cysts (5.2\%), 1 patient with liver cyst $(1.04 \%)$, and 1 patient with inspissated-bile syndrome (1. $04 \%)^{1}$

This study used medical record data of pregnant women who gave birth at Dr. Soetomo General Hospital, Surabaya from June 2016 to June 2017 and used chisquare analysis to find the relationship of infection to pregnant women with the incidence of cholestasis in infants.

\section{Methods}

The type of research used in this study was observational analytic with a case control design in Department of Pediatrics, Dr. Soetomo General Hospital, Surabaya. The population studied in this study were 178 infants aged 0-1 year old during June 2016 to June 2017 in Department of Pediatrics, Dr. Soetomo General Hospital, Surabaya. The population in this study was divided into a case population which included 68 infants with cholestasis, while the control population was 110 non-cholestatic born infants. The sample in this study were babies (aged 0-1 year old) born in Dr. Soetomo General Hospital, Surabaya for the period of June 2016 - June 2017. Samples taken from the population were divided into case samples and control samples.

Case samples taken in this study were determined by inclusion criteria, infants with cholestasis and complete medical record records aged 0-1 year old. The control samples examined in this study were determined by inclusion criteria, infants without cholestasis, and exclusion criteria which included a history of parents of infants with genetic abnormalities and complications of pregnancy.

The sampling technique in this study was conducted by purposive sampling from secondary data on the age of birth and medical records (in this case with cholestasis). The case sample was the total population of all cases, although control samples were taken from infants without cholestasis (aged 0-1 year old).

The variables used in this study were independent variables which included maternal infection history and sex of the baby, and dependent variable which included cholestasis.

Descriptive analysis was used to provide descriptions of data presented in table form. This analysis was used to describe the character of the baby born and the degree of presence of cholestasis. Inferential analysis used chisquare to examine the relationship of the age of birth of infants to the presence of cholestasis.

\section{Results}

The medical record data taken in this study were 178 pregnant women who gave birth at the Dr. Soetomo General Hospital from June 2016 to June 2017 which consisted of 68 pregnant women who gave birth to babies with cholestasis and 110 pregnant women who gave birth to babies without cholestasis.

Table 1. Correlation between maternal infection and cholestasis.

\begin{tabular}{|l|c|c|}
\hline & $\begin{array}{l}\text { Cholestasis } \\
\text { baby }(\mathrm{n})\end{array}$ & $\begin{array}{l}\text { Non-cholestasis } \\
\text { baby }(\mathrm{n})\end{array}$ \\
\hline $\begin{array}{l}\text { With maternal } \\
\text { infection }\end{array}$ & 50 & 13 \\
\hline $\begin{array}{l}\text { Without } \\
\text { maternal } \\
\text { infection }\end{array}$ & 18 & 97 \\
\hline
\end{tabular}

${ }^{*}$ chi-square test $p$ value $<0.001$ (significant $p<0.05$ ) 
Based on Table 1, pregnant women with cholestatic infants who had a history of pregnancy infection were $73.53 \%$ of the total pregnant women with cholestatic infants and $26.47 \%$ with no history of pregnancy infection. Pregnant women with non-cholestasis babies who had a history of pregnancy were $11.81 \%$ of the total pregnant women with non-cholestasis infants, and those who did not have a history of pregnancy infection were $88.19 \%$ of the total cases of control.

The results of the analysis using the chi-square statistical test to determine the relationship of maternal infection with the incidence of cholestasis obtained $p$ value of $<0.001$ where the significant value of $p<0.05$, meaning that it is related. The contingency coefficient value of 0.531 meant infection history in pregnant women is related to the incidence of cholestasis. Odds ratio with $95 \% \mathrm{Cl}$ of 20,726 meant pregnant women with a history of infection at pregnancy are more at risk of having cholestasis babies by 20,726 times compared to pregnant women with no history of infection during pregnancy.

Table 2. Correlation between sex and cholestasis.

\begin{tabular}{|l|c|c|}
\hline & $\begin{array}{l}\text { Cholestasis } \\
\text { baby }(\mathrm{n})\end{array}$ & $\begin{array}{l}\text { Non-cholestasis } \\
\text { baby }(\mathrm{n})\end{array}$ \\
\hline Male & 26 & 57 \\
\hline Female & 42 & 53 \\
\hline
\end{tabular}

Based on Table 2, most infants with cholestasis were female infants of $61.76 \%$ and male infants were $38.24 \%$ of the total infants with cholestasis, whereas non-cholestasis infants between male and female did not have a significant difference.

The results of the study with chi-square statistical tests to find the relationship of the sex of the baby with the incidence of cholestasis obtained $p$ value of 0.107 where the significant value of $p>0.05$, meaning that sex is not related to the incidence of cholestasis in infants.

\section{Discussion}

\section{Characteristics of research subjects}

Data taken from medical records in this study were 178 pregnant women who gave birth at the Dr. Soetomo General Hospital from June 2016 to June 2017 which consisted of 68 pregnant women who gave birth to babies with cholestasis and 110 pregnant women who gave birth to babies without cholestasis. Cholestasis and not cholestasis babies which were included in the criteria in the study were $0-1$ year old infants.

\section{Maternal infection and cholestasis}

An infection that enters the liver or outside the liver, bacteria can produce endotoxins that can enter the circulation even though infecting bacteria do not enter the bloodstream. The condition of cholestasis can be found even though there is no bacteremia. Endocytin can stimulate cytokine synthesis by macrophages (in the liver such as kupffer cells). Kupffer cells and other immunocompetent cells in the liver synthesize intrahepatic cytokines such as TNF- $\alpha, \mathrm{IL}-1, \mathrm{IL}-6$, and IL-8, thus intrahepatic cytokines increase in number, interfere with hepatocyte function, and cause cholestasis. ${ }^{3}$

The results of the study at Dr. Hospital Soetomo in June 2016-June 2107 showed that pregnant women with cholestasis babies who had a history of pregnancy infection were $73.53 \%$ of the total pregnant women with cholestasis babies, while pregnant women with non-cholestasis babies who had a history of pregnancy infection were $11.81 \%$ of the total pregnant women with not cholestatic babies.

The results of the study using chi-square statistical tests to determine the relationship of infection history to pregnant women with the incidence of cholestasis obtained $p$ value of $<0.001$ which was $p<0.05$ with a contingency coefficient of 0.531 , meaning infection history in pregnant women, and odds ratio with $\mathrm{Cl} 95 \%$ of 20,726 , meaning that pregnant women with a history of infection during pregnancy are more at risk of having a cholestatic baby by 20,726 times compared to pregnant women with no history of infection during pregnancy.

\section{Sex and cholestasis}

This study on 68 infants who experienced cholestasis during the period of June 2016 to June 2017 at Dr. Soetomo General Hospital showed that most babies with cholestasis were female babies with $61.76 \%$ and male babies were $38.34 \%$ of the total babies with cholestasis, whereas infants without cholestasis between male and female did not have a significant difference.

The results of the study with chi square statistical tests to find the relationship of the sex of the baby with the incidence of cholestasis obtained $p$ value 0.107 where $p>$ 0.05 , meaning that sex is not related to the incidence of cholestasis in infants.

\section{Conclusion}

The number of infants with cholestasis was higher in the group of infants with mothers who had a history of pregnancy infection by $73.53 \%$ of the total cholestatic infants in Dr. Soetomo General Hospital from June 2016 June 2017. According to sex, $61.76 \%$ of total cholestatic infants were female infants and male infants were only $38.24 \%$.

There is a significant relationship between the history of maternal infection and the incidence of cholestasis in infants and there is no correlation between sex and the incidence of cholestasis in Department of Pediatrics Dr. Soetomo General Hospital, Surabaya in the period of June 2016 - June 2017. 


\section{CONFLICT OF INTEREST}

The author stated there is no conflict of interest in this study.

\section{REFERENCES}

1. Arief S, Hernik R, Nugrohowidhi A and Hidayat B. A Cholestatic Type of Hepatitis A in a Child. Paediatrica Indonesiana. 2001; 41: 308-10.

2. Moyer V, Freese DK, Whitington PF, et al. Guideline for the Evaluation of Cholestatic Jaundice in Infants: Recommendations of the North American Society for Pediatric Gastroenterology, Hepatology and Nutrition. Journal of Pediatric Gastroenterology and Nutrition. 2004; 39: 115-28.

3. Oswari $\mathrm{H}$, Harijadi $\mathrm{H}$, Bisanto $\mathrm{J}$ and Purnamawati $\mathrm{S}$. Infeksi Saluran Kemih sebagai Penyebab Kolestasis Intrahepatik. Sari Pediatri. 2016; 6: 166-71.

4. Petersen $C$ and Davenport M. Aetiology of Biliary Atresia: What is actually Known? Orphanet Journal of Rare Diseases. 2013; 8: 128.

5. Fischler B, Svensson JF and Nemeth A. Early Cytomegalovirus Infection and the Long-Term Outcome of
Biliary Atresia. Acta Paediatrica (Oslo, Norway : 1992). 2009; 98: 1600-2.

6. Xu Y, Yu J, Zhang R, et al. The Perinatal Infection of Cytomegalovirus is an Important Etiology for Biliary Atresia in China. Clinical Pediatrics. 2012; 51: 109-13.

7. De Tommaso AM, Andrade PD, Costa SC, Escanhoela $C A$ and Hessel G. High Frequency of Human Cytomegalovirus DNA in the Liver of Infants with Extrahepatic Neonatal Cholestasis. BMC Infectious Diseases. 2005; 5: 108.

8. Zani A, Quaglia A, Hadzić N, Zuckerman M and Davenport M. Cytomegalovirus-Associated Biliary Atresia: An Aetiological and Prognostic Subgroup. Journal of Pediatric Surgery. 2015; 50: 1739-45.

9. Rauschenfels S, Krassmann M, Al-Masri AN, et al. Incidence of Hepatotropic Viruses in Biliary Atresia. European Journal of Pediatrics. 2009; 168: 469-76.

10. Xu X, Rahbar A, Omarsdottir S, et al. CD13 Autoantibodies are Elevated in Sera From Mothers of Infants with Neonatal Cholestasis of Different Causes. Journal of Pediatric Gastroenterology and Nutrition. 2017; 64: 76-82.

11. Nazer H. Cholestasis: Background, Pathophysiology, Epidemiology: (2017, accessed 24 November 2018). 